\title{
Outcome of Pertrochanteric Femur Fractures with Proximal Femur Locking Compression Plate
}

\author{
Iqbal Singh ${ }^{1}$, Manpreet Singh $^{2^{*}}$, Ranbir Singh $^{3}$
}

${ }^{1}$ Assistant Professor, Department of Orthopaedics, GNDH, Amritsar, Punjab, India.

Email: isghai@gmail.com

Orcid ID: 0000-0002-1507-7532

2Senior Resident, Department of Orthopaedics, GNDH, Amritsar,

Punjab, India.

Email: drmps115@gmail.com

Orcid ID: 0000-0002-0040-3817.

3Senior Resident, Department of Orthopaedics, GNDH, Amritsar,

Punjab, India.

Email: drranbir@gmail.com

Orcid ID: 0000-0001-5323-2540.

*Corresponding author

Received: 09 May 2021

Revised: 25 June 2021

Accepted: 01 July 2021

Published: 22 December 2021

\begin{abstract}
Background: Fractures of the proximal femur, including fractures affecting the pertrochanteric region, have become a public health problem. Owing to aging of the population, we have to operate on even more elderly patients who sometimes present with significant co-morbidities. Although conventional implants have given good results in stable peritrochanteric fractures, proximal femur locking compression plate (PFLCP) which has been recently introduced is better suited for comminuted, unstable pertrochanteric fractures and osteoporotic bones. In PF-LCP, bone-implantconstruct so formed is mechanically stable and fixation failure due to screw loosening in osteoporotic bone can be reduced. Materials \&Methods: This prospective study was conducted in our institute and was approved by local ethical committee. Twenty-five consecutive patients of either sex with age more than 60 years (range, 60-84) having pertrochanteric fractures were operated upon with PFLCP. A.O classification was followed in the study and Singh's index for osteoporosis was calculated. Operating time, blood loss and any technical difficulty with the implant were recorded. Patients were followed clinically and radiologically for union at fracture site and implant-related complications for a period of 24 months. The Harris Hip Score was used to document hip functions at final follow-up. Observations: Amongst the 25 patients, the average operation time in our study was $66.60 \pm 10.57$ minutes. The average radiological union was $3.40 \pm 0.63$ months (13.6 weeks). Average time for full weight bearing was $13.12 \pm 1.90$ weeks. There were two cases of wound infection, one case of coxa vara and one case of a proximal screw back-out. There was no case of plate lift or screw breakage. There was no case of non-union. Conclusion: The PFLCP can be a feasible alternative to the treatment of peritrochanteric fractures. Treatment with PFLCP can provide good-to-excellent healing in osteoporotic bones having comminuted and unstable peritrochanteric fractures, with a limited occurrence of complications.
\end{abstract}

Keywords:- Pertrochanteric fractures, Osteoporosis, Internal fixation, PF-LCP.

\section{INTRODUCTION}

Aided by the advances of the modern medical science, expectancy of life of people over the world has increased and the incidence of peritrochanteric fractures has been on the rise because of osteoporotic bones of the elderly people which get easily fractured.[1] These fractures are more common in females than in males probably as a result of several factors like wider pelvis in women leading to tendency for coxa vara, women being less active develop osteoporosis which is further enhanced by post-menopausal changes.[1,2] 
Annals of International Medical and Dental Research

E-ISSN: 2395-2822 | P-ISSN: 2395-2814

Vol-8, Issue-1 | January-February 2022

DOI: 10.53339/aimdr.2022.8.1.33

Page no- 253-260 | Section- Research Article (Orthopaedics)

Majority of these fractures occur due to direct trauma and major chunk of it is due to a simple fall. Hip fractures can lead to severe morbidity and mortality especially in older adults. Allowing patients to get out of bed earlier and promoting early mobilization is necessary to prevent complications such as deep vein thrombosis, bed sores, pulmonary infection and muscle atrophy. Therefore, treatment should be so planned as to get union without deformity and early mobilization of the patient. What must be remembered is that osteoporotic bones have distinct morphological characteristics that influence its biomechanical properties and therefore the choices and techniques for internal fixation should be well planned out. [3]

Various implants which are commonly used for fixation of these fractures are sliding hip screw (DHS), cephalo-medullary nails (PFN, PFNA-II, Gamma Nails) and angular blade plates. PF-LCP is part of new generation of plates developed in an effort to increase early mobilization of patients. They are theoretically superior to intramedullary nails because they can be applied with less bone injury and provide stabilization through placement of more screws at different angles into the proximal part of femur. These plates provide angular as well as rotational stability making them ideal for less stable and comminuted fractures. PF-LCP can also be slid subperiosteally without much dissection thus reducing the operation time and bleeding which is advantageous as elderly patients have poor cardiac reserves. [4]

\section{MATERIAL AND METHODS}

This prospective study conducted from July 2015 to October 2017, included 25 elderly patients ( 9 males and 16 females) above the age of 60 years with pertrochanteric fractures admitted in our hospital. This was done to focus our study on osteoporotic bones in the elderly. Only closed fractures without any neurovascular compromise or intra-articular extension were considered. Our exclusion criteria included patients below 60 years of age, previous fracture around proximal femur, multiple fractures, open fractures, fractures more than 3 weeks old and patients with multiple comorbidities. After admission all the patients were thoroughly assessed for any other injury and a comprehensive muscle skeletal examination along with detailed history taken. Plain X-ray was done for AP view of pelvis including both hips and also of femur including the knee joints. Skin traction was applied to immobilize the limb and necessary investigations were done for anaesthetic fitness for surgery. Since our study involves elderly persons, all the patients were listed for surgery only after anaesthetic clearance and investigations like echocardiography were done when required. All patients were evaluated for osteoporosis and were given scores according to Singh's index.

\section{Operative technique:}

All the patients in our study were operated with PF-LCP. Under spinal anaesthesia and aseptic conditions, patient was put on spica table and contralateral leg was placed on leg holder. Closed reduction was achieved by giving traction and it was checked under carm in both AP and lateral view. In highly comminuted and unstable fractures that could not be reduced adequately by closed reduction, we reduced them intra-operatively.

A direct lateral 10-12 cm incision was given starting from the tip of greater trochanter and extending distally. Then subcutaneous tissue and iliotibial band was cut in line with the skin incision opening vastus lateralis muscle. We 
Annals of International Medical and Dental Research

E-ISSN: 2395-2822 | P-ISSN: 2395-2814

Vol-8, Issue-1 | January-February 2022

DOI: 10.53339/aimdr.2022.8.1.33

Page no- 253-260 | Section- Research Article (Orthopaedics)

preferred to elevate the vastus lateralis off and used pointed reduction forceps to maintain the reduction. If needed bone hooks or bone spikes were used to get satisfactory reduction. Then PF-LCP was placed on the lateral aspect of proximal femur across the fracture site. Plate was temporarily fixed to shaft by Kwires and both alignment of plate and reduction was checked in AP and lateral views. Guide wires were inserted through guide sleeve in proximal hooded portion. After getting the desired position of guide wires in AP and lateral views, drill holes were made using cannulated drill bits over guide wires and appropriate size screws were inserted upto the subchondral bone. Position and length of all the screws was rechecked under c-arm in both AP and lateral views. The plate was then fixed distally to the femoral shaft with a minimum of 3-4 screws. In comminuted fracture, holes at the fracture site were left empty to increase working length. Wound was closed in layers over a suction drain. Drain was removed on $3^{\text {rd }}$ postoperative day. Post-operatively patients were given quadriceps exercises and allowed nonweight bearing ambulation 2 days after the surgery. Toe touch weight bearing was started at 4 weeks and full weight bearing at 8 weeks, subject to union criteria. Patients were followed up at 4 weekly intervals for first three months and looked-for signs of union, varus collapse, hardware failure and limb shortening.

\section{RESULTS}

In our study, 25 patients were considered, all above the age of 60 years. Minimum and maximum age in our study was 60 and 84 years respectively, with average age of 69.08 years. Our sample was such taken so that we could do our study in osteoporotic bones. In our study females have outnumbered males with a ratio of $1.77: 1$. Out of 25 cases, there were 16 females (64\%) and 9 males (36\%).

In our study, majority of patients 18 (72\%) (out of 25 cases) have suffered injury through fall (low energy trauma) and rest of the patients 7 (28\%) (out of 25 cases) suffered injury because of high energy trauma (RTA, assault).

In our study as per A.O classification, [] $\mathrm{A}$ 1 fractures constituted $48 \%$, A2 comprising of $44 \%$ and $\mathrm{A} 3$ comprising of $8 \%$ as shown in Table 1. In Table 2, as per Singh's index we had $24 \%$ patients in Grade 1 osteoporosis, 36\% in Grade 2 and 28\% in Grade 3.66] There were 4\% and $8 \%$ cases in Grade 4 and 5 respectively. Mean time interval between injury and surgery was $5.36 \pm 2.93$ days. Average time of surgery was 50-70 minutes with mean being $66.60 \pm 10.57$ minutes as shown in Table 3. Most of the patients were mobilized by $3^{\text {rd }}$ postoperative day and were discharged by $10^{\text {th }}$ post-operative day. Most of the patients were able to bear full weight between 12-15 weeks with mean of $13.12 \pm 1.90$ weeks. We followed up the patients from 08-22 months in this study. The range of motion at 6 months follow up was ranging from $160-225^{\circ}$ with mean of 205.2 \pm 15.17 degrees. As per Harris Hip Score, 7$]$ most of the patients in our study had good to excellent results (88\%).Only $12 \%$ had fair to poor results in our study as shown in [Table 4].

In higher grades of osteoporosis, excellent results were observed in $50 \%$ of patients in Grade 1 and 55\% in Grade 2, indicating that locking plate gives better results in osteoporotic patients, while in patients with lower grades of osteoporosis i.e. 3,4 and 5, excellent results were observed in $28.5 \%, 100 \%$ and $50 \%$ respectively. Two patients (8\%) developed wound infection, one superficial $(4 \%)$ and one deep $(4 \%)$. One patient $(4 \%)$ 
Annals of International Medical and Dental Research

E-ISSN: 2395-2822 | P-ISSN: 2395-2814

Vol-8, Issue-1 | January-February 2022

DOI: 10.53339/aimdr.2022.8.1.33

Page no- 253-260 | Section- Research Article (Orthopaedics)

developed coxa vara and one patient $(4 \%)$ had screw back-out of one of the proximal hood screws of PF-LCP.

Table 1: Distribution as Per A.O Classification

\begin{tabular}{|c|c|c|c|c|c|c|}
\hline \multirow[t]{3}{*}{ A.O. Classification } & \multicolumn{3}{|l|}{ Sex } & \multicolumn{3}{|c|}{ Total } \\
\hline & \multicolumn{2}{|c|}{ Male } & \multicolumn{2}{|c|}{ Female } & \multirow[t]{2}{*}{ No. } & \multirow[t]{2}{*}{ \%age } \\
\hline & No. & $\%$ & No. & $\%$ & & \\
\hline A1.1 & 2 & 8.0 & 5 & 20.0 & 7 & 28.0 \\
\hline A1.2 & 0 & 0 & 2 & 8.0 & 2 & 8.0 \\
\hline A1.3 & 1 & 4.0 & 2 & 8.0 & 3 & 12.0 \\
\hline A2.1 & 2 & 8.0 & 3 & 12.0 & 5 & 20.0 \\
\hline A2.2 & 2 & 8.0 & 1 & 4.0 & 3 & 12.0 \\
\hline A2.3 & 1 & 4.0 & 2 & 8.0 & 3 & 12.0 \\
\hline A3.1 & 0 & 0 & 1 & 4.0 & 1 & 4.0 \\
\hline A3.2 & 1 & 4.0 & 0 & 0 & 1 & 4.0 \\
\hline A3.3 & 0 & 0 & 0 & 0 & 0 & 0 \\
\hline
\end{tabular}

Table 2: Singh's Grading of Osteoporosis

\begin{tabular}{|l|c|c|}
\hline Singh's grade of osteoporosis & No. & \%age \\
\hline I & 6 & 24.0 \\
\hline II & 9 & 36.0 \\
\hline III & 7 & 28.0 \\
\hline IV & 1 & 4.0 \\
\hline V & 2 & 8.0 \\
\hline Total & 25 & 100.0 \\
\hline
\end{tabular}

Table 3: Duration of Surgery

\begin{tabular}{|l|l|l|}
\hline Duration in minutes & No. & \%age \\
\hline $50-60$ & 8 & 32.0 \\
\hline $60-70$ & 7 & 28.0 \\
\hline $70-80$ & 6 & 24.0 \\
\hline $80-90$ & 4 & 16.0 \\
\hline Total & 25 & 100.0 \\
\hline Mean duration of surgery & $66.80 \pm 10.57$ & \\
\hline
\end{tabular}

Table 4: Final Results As Per Modified Harris Hip Score

\begin{tabular}{|l|l|l|}
\hline Results & No. & \%age \\
\hline Excellent & 12 & 48.0 \\
\hline Good & 10 & 40.0 \\
\hline Fair & 2 & 8.0 \\
\hline Poor & 1 & 4.0 \\
\hline Total & 25 & 100.0 \\
\hline
\end{tabular}




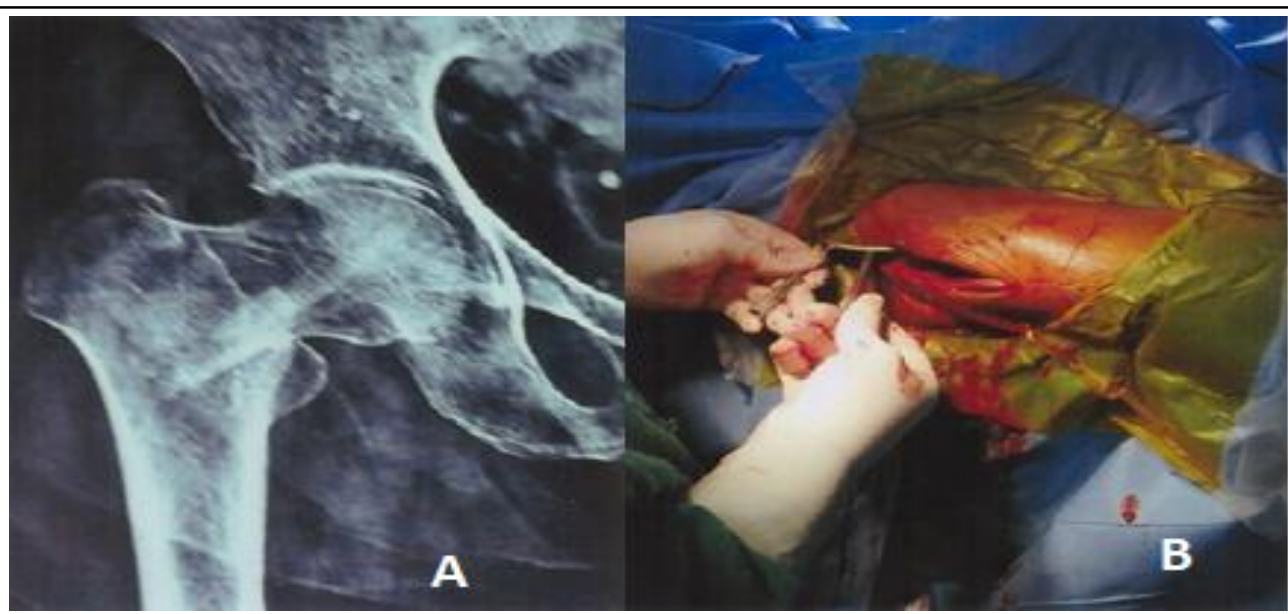

Figure 1: A) Pre-Operative X-Ray, B) Placement of Guide Wires into Neck Femur

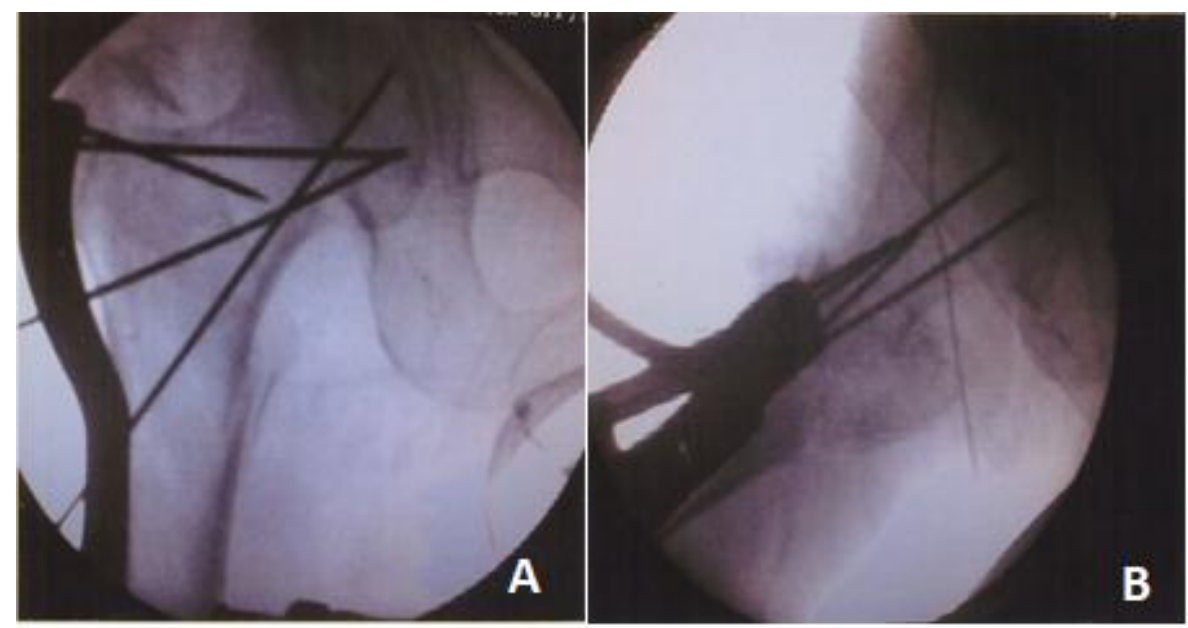

Figure 2: Placement of Guide Wires into Neck Femur in AP \& Lateral Views Under Image Intensifier

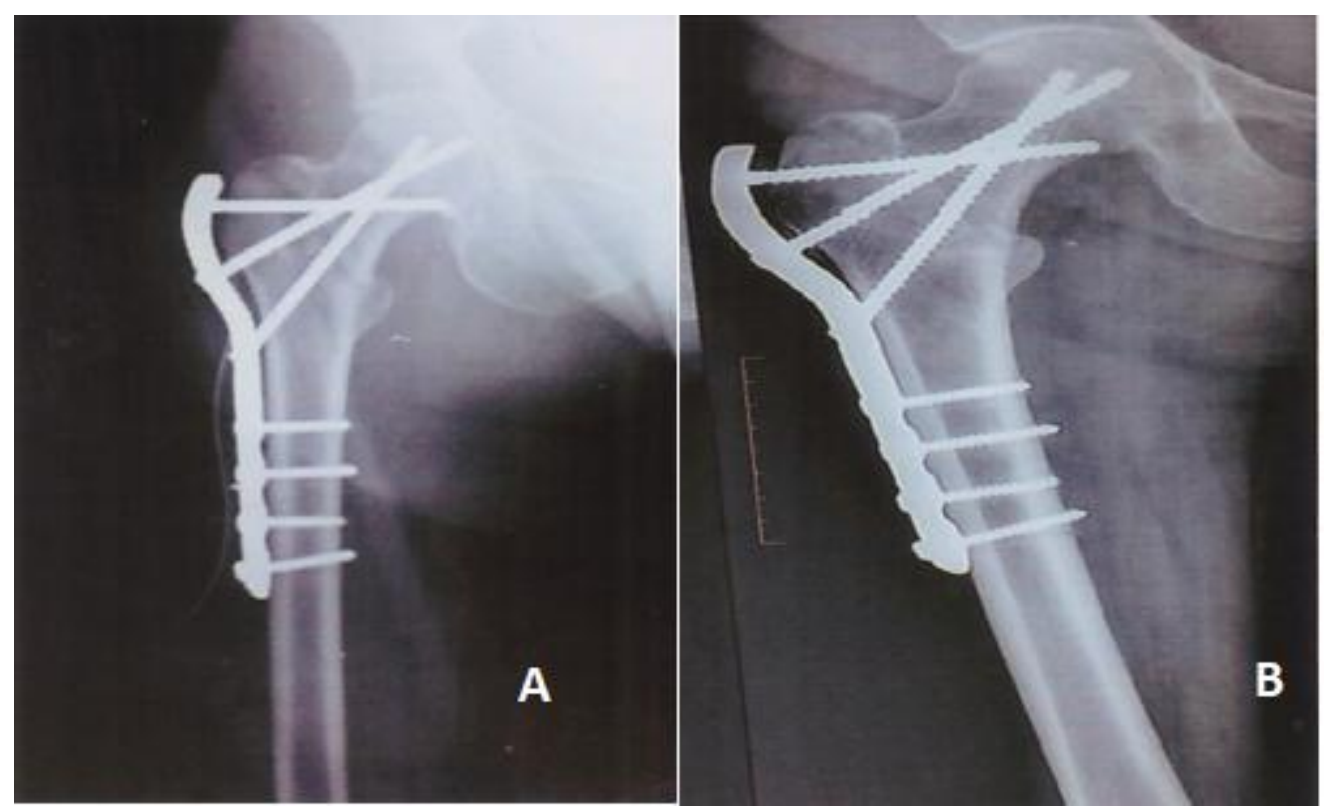


Figure 3: A) First Post-Operative Day X-Ray, B) After 6 Months Final Clinical Outcome

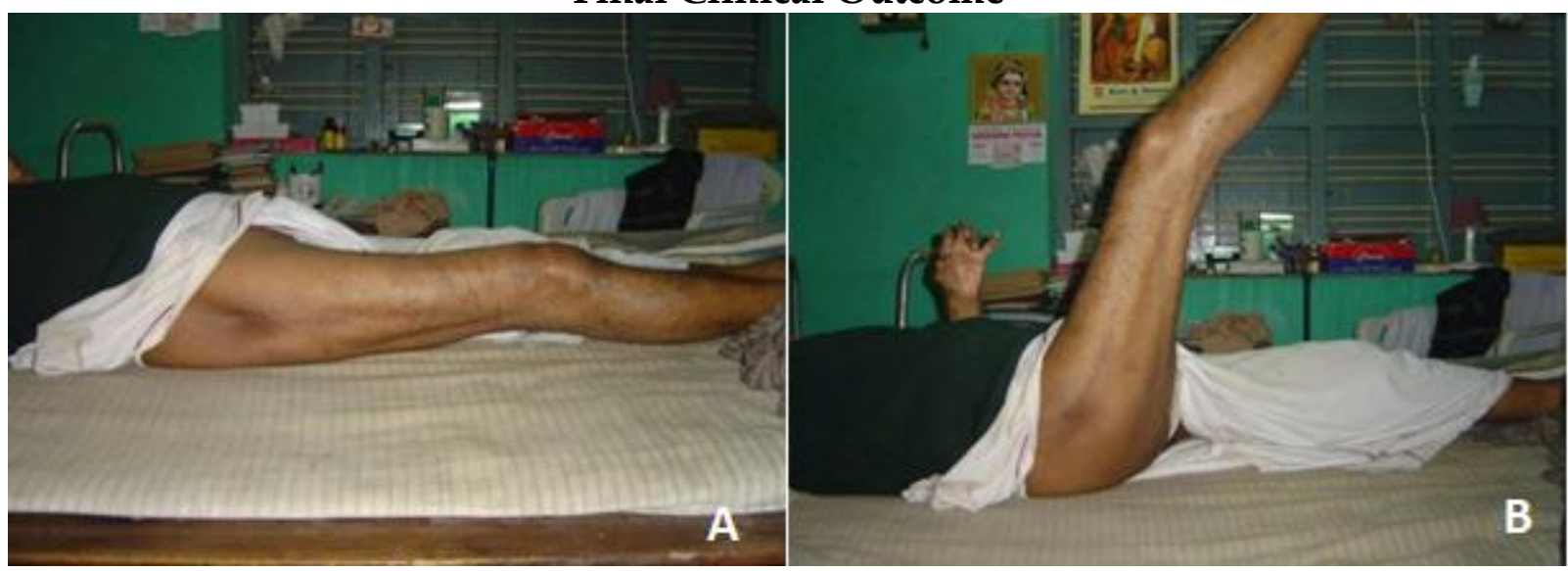

Figure 4: A) Extension, B) Flexion

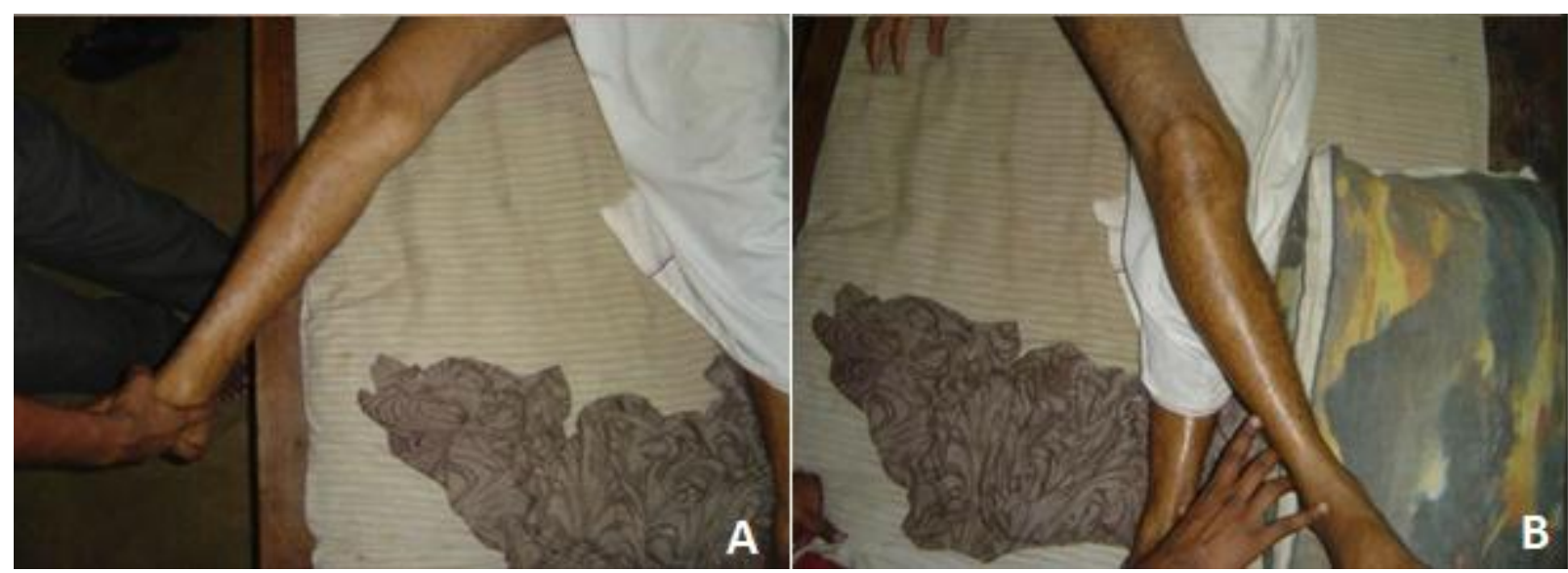

Figure 5: A) Abduction, B) Adduction

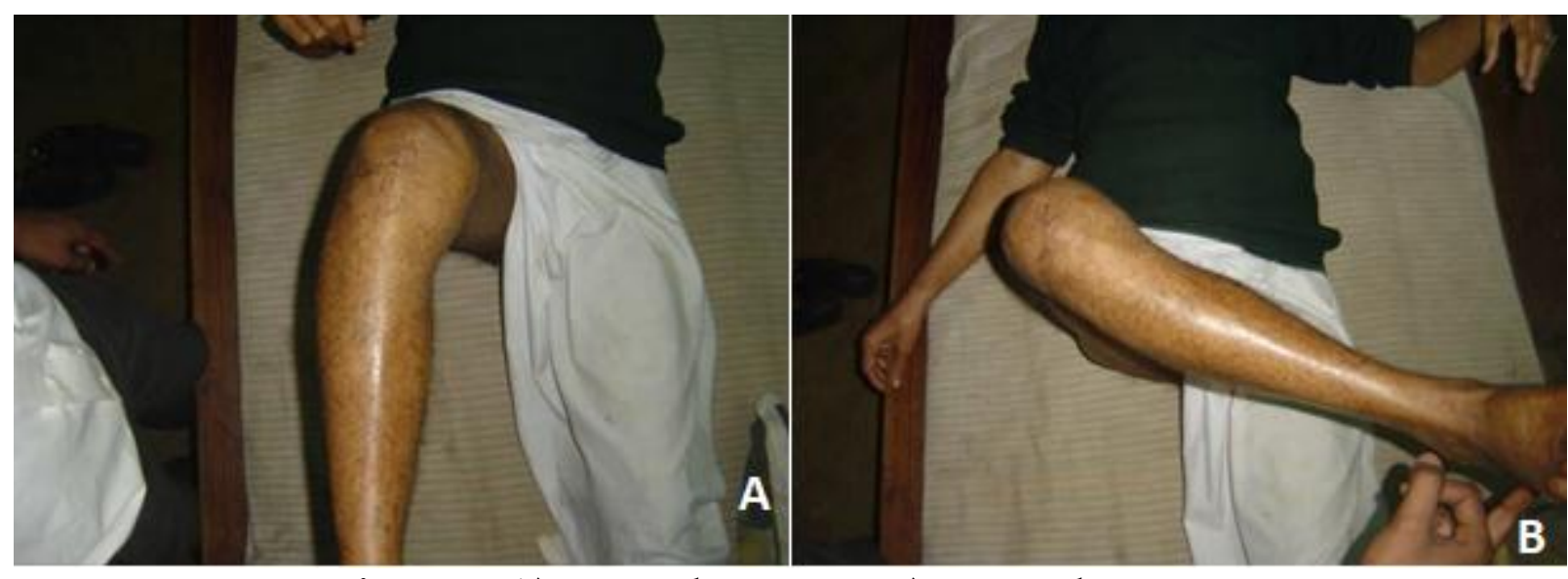

Figure 6: A) Internal Rotation, B) External Rotation 
Annals of International Medical and Dental Research

E-ISSN: 2395-2822 |P-ISSN: 2395-2814

Vol-8, Issue-1 | January-February 2022

DOI: 10.53339/aimdr.2022.8.1.33

Page no- 253-260 | Section- Research Article (Orthopaedics)

\section{DISCUSSION}

In the present study, 25 patients of pertrochanteric fracture of femur above the age of 60 years were considered. Our sample was such taken that we could do our study in osteoporotic bones. The best treatment of these fractures is debatable. The aim of study was to achieve union at the fracture site and lower the usual complications associated with its fixation. Objective of our treatment is early mobilization and weight bearing so that patient can regain their pre-injury functional status. To achieve such goals, we need an implant which has an inherently stable construct independent of bone quality and does minimum damage to the vascular supply of the bone and has low complication rate. PFLCP helps us to achieve that goal.

Recently PF-LCP has been introduced as a new implant that allows angular stable plating for the treatment of complex comminuted and osteoporotic fractures. This plate acts as a fixed angle internal fixator and achieves greater stability compared with DHS/DCS/Angle blade plate while avoiding excessive bone removal and is ideal in osteoporotic bones. $[7,8,9]$ Proximal locking

\section{REFERENCES}

1. Cumming RG, Nevitt MC, Cummings SR. Epidemiology of hip fractures. Epidemiol Rev. 1997;19(2):244-57. doi: 10.1093/oxfordjournals.epirev.a017956.

2. Michelson JD, Myers A, Jinnah R, Cox Q, Van Natta M. Epidemiology of hip fractures among the elderly. Risk factors for fracture type. ClinOrthopRelat Res. 1995;(311):129-35.

3. WilligR, Keinänen-Kiukaaniemi S, Jalovaara P. Mortality and quality of life after trochanteric hip fracture. Public Health. 2001;115(5):323-7. doi: 10.1038/sj.ph.1900773.

4. HaidukewychGJ. Innovations in locking plate technology. J Am AcadOrthop Surg. 2004;12(4):20512. doi: 10.5435/00124635-200407000-00001. screws of this plate provide angular stable construct independent of bone quality. Varied angle of multiple screw insertions within the complex trabecular zone of the head neck region of proximal femur provides an optimal mechanical stability. It also prevents rotational instability and allows angular stability. Its 120$135^{\circ}$ screws provide calcar stability and maintain neck-shaft angle thus prevents varus collapse. It also substitutes for an incompetent lateral cortex. Our results showed minimum varus collapse and no hardware failure. $[10,11,12,13,14]$

Our study is a unique study describing a new technique with new implant, secondly the data analysed here pertain to osteoporotic bones in the elderly persons. It has one limitation also that it is a case series and not a comparison between the surgical techniques in randomized fixation.

\section{CONCLUSION}

PF-LCP is an effective implant for pertrochanteric fractures of femur as it provides angular stability with early functional rehabilitation and fixed angle block.
5. HeskethT, Xing ZW. Abnormal sex ratios in human populations: causes and consequences. Proc Natl AcadSci U S A. 2006;103(36):13271-13275. doi:10.1073/pnas.0602203103

6. Singh M, Nagrath AR, Maini PS. Changes in trabecular pattern of the upper end of the femur as an index of osteoporosis. J Bone Joint Surg Am. 1970;52(3):457-67.

7. OvreS, Sandvik L, Madsen JE, Roise O. Modification of the Harris Hip Score in acetabular fracture treatment. Injury. 2007;38(3):344-9. doi: 10.1016/j.injury.2006.04.129.

8. HasenboehlerEA, Agudelo JF, Morgan SJ, Smith WR, Hak DJ, Stahel PF. Treatment of complex proximal femoral fractures with the proximal femur 
Annals of International Medical and Dental Research

E-ISSN: 2395-2822 |P-ISSN: 2395-2814

Vol-8, Issue-1 | January-February 2022

DOI: 10.53339/aimdr.2022.8.1.33

Page no- 253-260 | Section- Research Article (Orthopaedics)

locking compression plate. Orthopedics. 2007;30(8):618-23. doi: 10.3928/01477447-2007080118.

9. Kumar N, Kataria H, Yadav C, Gadagoli BS, Raj R. Evaluation of proximal femoral locking plate in unstable extracapsular proximal femoral fractures: Surgical technique \&mid termfollow up results. J ClinOrthop Trauma. 2014;5(3):137-45. doi: 10.1016/j.jcot.2014.07.009.

10. ZhaGC, Chen ZL, Qi XB, Sun JY. Treatment of pertrochanteric fractures with a proximal femur locking compression plate. Injury. 2011;42(11):12949. doi: 10.1016/j.injury.2011.01.030.

11. Johnson B, Stevenson J, Chamma R, Patel A, Rhee SJ, Lever C, et al. Short-term follow-up of pertrochanteric fractures treated using the proximal femoral locking plate. J Orthop Trauma. 2014;28(5):283-7.

doi: 10.1097/01.bot.0000435629.86640.6f.
12. Lee WT, Murphy D, Kagda FH, Thambiah J. Proximal femoral locking compression plate for proximal femoral fractures. J OrthopSurg (Hong Kong). 2014;22(3):287-93. doi: $10.1177 / 230949901402200304$.

13. Ibrahim S, Meleppuram JJ. A retrospective analysis of surgically-treated complex proximal femur fractures with proximal femoral locking compression plate. Rev Bras Ortop. 2017;52(6):644650. doi:10.1016/j.rboe.2016.12.012

14. Shah MD, Kapoor CS, Soni RJ, Patwa JJ, Golwala PP. Evaluation of outcome of proximal femur locking compression plate (PFLCP) in unstable proximal femur fractures. J ClinOrthop Trauma. 2017;8(4):308312. doi: 10.1016/j.jcot.2016.11.005.

Source of Support: Nil, Conflict of Interest: None declared 